\title{
Difficulties in indicating appendectomy; diagnosis of appendicitis in patients with normal white blood cell count
}

\author{
Veli VURAL \\ Department of General Surgery, School of Medicine, Akdeniz University Hospital, Antalya, Turkey
}

Corresponding Author: Veli VURAL_Ｅ-mail: velivural1980@hotmail.com

Submitted: $12.09 .2019 \quad$ Accepted: 11.11.2019

\begin{abstract}
Objectives: Even after 130 years have passed since the first appendectomy, diagnosing acute appendicitis can still be challenging. The objective of this study was to investigate clinical, imaging and laboratory findings of patients diagnosed with acute appendicitis in order to determine whether white blood cell count is helpful in the diagnosis.

Materials and Methods: Parameters of Alvarado score, patients' complaints, physical examination and laboratory findings were recorded. Appendiceal diameters of patients detected with ultrasound (US) were also recorded.

Results: Of the 98 patients, 89 patients (91\%) had an appendiceal diameter wider than $8 \mathrm{~mm}$ and 9 patients (9\%) had an appendiceal diameter of $8 \mathrm{~mm}$ and smaller in the preoperative US. Pathology was normal in 8 out of 9 patients (89\%) with a diameter of $8 \mathrm{~mm}$ and below; and 9 out of 89 patients (9\%) with a diameter above $8 \mathrm{~mm}(\mathrm{p}<0.05)$. Sensitivity and specificity of the 8 -mm cut-off was $99 \%$ and $47 \%$ respectively. Positive and negative predictive values were $90 \%$ and $89 \%$ respectively.

Conclusion: Distribution of pathology results with respect to appendiceal-diameters revealed that there was an obvious threshold between normal and pathology-proven appendicitis. This outcome highlights the importance of imaging in the diagnosis.

Keywords: Appendicitis, Diagnostic ultrasound, White blood cell count
\end{abstract}

\section{INTRODUCTION}

In 1880, Robert Lawson Tait performed the first appendectomy for appendicitis in the United Kingdom [1]. Even after 130 years, diagnosing acute appendicitis can still be challenging for surgeons. This is demonstrated by high negative laparotomy rates documented in different literature. In a Swedish study, female and male patients had negative appendectomy rates of $24 \%$ and $12 \%$, respectively [2]. In another large North American study, the rate of negative appendectomy was $13 \%$ [3]. It is assumed that negative laparotomy rate decreases to approximately 10 by routine use of ultrasonography (US) [4]. The higher sensitivity of computed tomography (CT) seems to have a greater impact on the rate of negative laparotomies, which has reduced the estimated rate by $5-10 \%[4,5]$. In most European countries, most surgeons consider acute appendicitis as a clinical diagnosis and do not routinely perform imaging techniques [6].

Scoring systems are designed to assist the clinical evaluation of patients with acute appendicitis (AA). The Alvarado score, even though there are some disadvantages, is the most common scoring system and its use is validated in several studies [79]. The structure was based on a review of patients who were operated after suspicion of appendicitis, whereas the score should be used in all patients with suspected appendicitis. Furthermore, the score does not contain C-reactive protein as a variable, but many studies have demonstrated the importance of $\mathrm{C}$-reactive protein in the evaluation of patients with appendicitis [10].

The recent appendicitis inflammatory response (AIR) score is designed to overcome these disadvantages [11].

The white blood cell count (WBCC) in the diagnosis of AA is neither sensitive nor specific. WBCC is high in almost $70 \%$ of the spectrum of etiologies causing right lower abdominal pain [10]. The use of imaging techniques reduced the rate of negative appendectomy. However, it is accepted that WBCC alone is not sufficient $[10,12]$.

In this study, we aimed to investigate the clinical, imaging and laboratory findings of patients diagnosed with AA in order to determine whether WBCC is helpful in the diagnosis of future cases.

How to cite this article: Vural V. Difficulties in indicating appendectomy; diagnosis of appendicitis in patients with normal white blood cell count. Marmara Med J 2020;33: 35-38. doi: 10.5472/marumj.681990 


\section{MATERIAL and METHODS}

This study included 436 patients (patients with complete records of related medical information) who were operated on in our surgical clinic between January 2015 and September 2018 with the diagnosis of AA. Approval for this study was obtained from Akdeniz University, School of Medicine Clinical Research Ethics Committee (approval number 917) .

We excluded patients with incomplete clinical information.

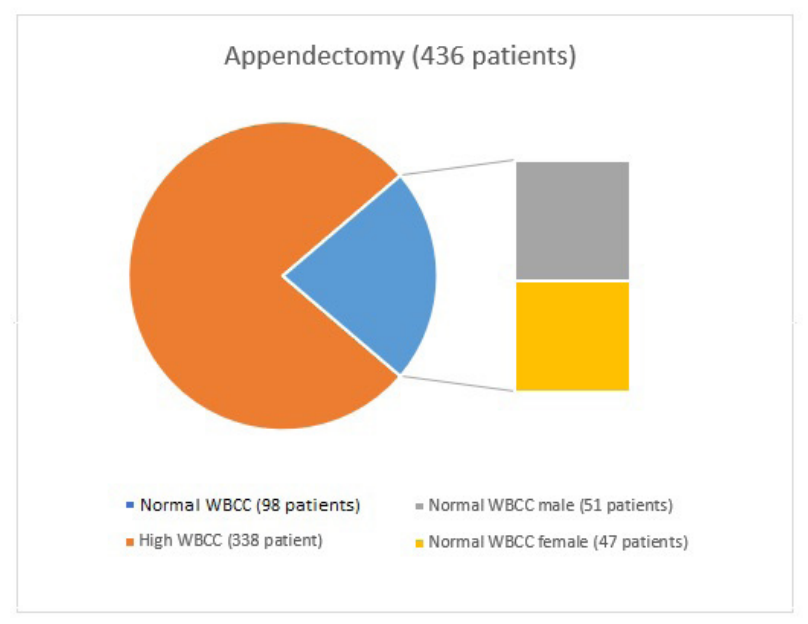

Figure 1. The white blood cell count distribution of patients who underwent appendectomy during the study period.

Complaints and physical examination findings of the patients were obtained from their medical files. Patients with hematological disease, immunosuppression and malignancy were excluded from the study. In addition, the parameters of Alvarado score were evaluated and patients' complaints, physical examination findings and laboratory findings were recorded retrospectively. Appendiceal diameters of patients with normal WBCC were also recorded. These diameters were calculated based on the abdominal images taken before the operation. Whole blood samples were collected in $4 \mathrm{~mL}$ K2EDTA tubes and leukocyte count was performed by optical method using an automatic hematology analyzer. Pathology samples were divided into two groups as normal appendix and appendicitis.

\section{Statistics Analysis}

In the statistical analysis of data, Statistical Package for Social Sciences for Windows (SPSS Inc., Chicago, Illinois, USA) version 16.0 was used. In addition to the descriptive statistical methods (mean, standard deviation), for the intergroup comparison of normally distributed parameters of quantitative data and for non-normally distributed parameters the Student's t-test and the Mann-Whitney U-test were used. The relationships between numerical data were analyzed by a correlation analysis. Qualitative data were compared using the Chi-square test.

\section{RESULTS}

Throughout the study period, out of 436 patients who underwent appendectomy, only 98 patients had a normal WBCC. Of these, $51(52 \%)$ were male and $47(48 \%)$ female (Figure 1). The mean age of the patients was $36 \pm 11(\min 18, \max 72)$.

According to pathology reports, 81 patients (83\%) had AA and 17 patients (17\%) had normal results. Of the 98 patients, 89 patients (91\%) had an appendiceal diameter wider than $8 \mathrm{~mm}$ US and 9 patients (9\%) had an appendiceal diameter of $8 \mathrm{~mm}$ and smaller in the preoperative US. Pathology was normal in 8 out of 9 patients (89\%) with a diameter of $8 \mathrm{~mm}$ and below; and 9 out of 89 patients (9\%) with a diameter above $8 \mathrm{~mm}$. This difference was statistically significant $(\mathrm{p}<0.05)$. Sensitivity and specificity of the 8 -mm cut-off was found to be $99 \%$ and $47 \%$ respectively. Positive and negative predictive values were $90 \%$ and $89 \%$ respectively. Accuracy diagram of ultrasound guided diagnosis of acute appendicitis revealed a threshold of 8-mm for appendiceal diameter (Figure 2).

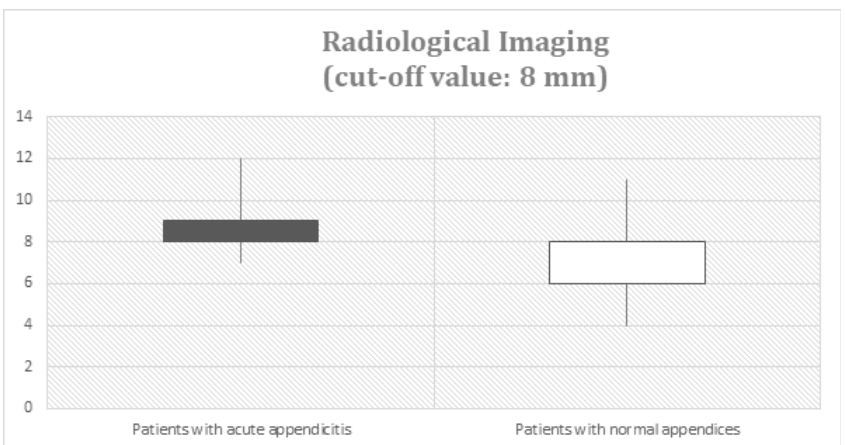

Figure 2. Accuracy diagram of ultrasound guided diagnosis of acute appendicitis revealing the importance of $8-\mathrm{mm}$ threshold for appendiceal diameter $(\mathrm{p}<0.05)$.

The rate of negative exploration was $17 \%$ and all were reported as pathological end-stage lymphoid hyperplasia. In the univariate analysis, neutrophil count, appendix diameter and Alvarado score were statistically significant $(\mathrm{p}<0.05)$.

\section{DISCUSSION}

In this study, distribution of pathology results with respect to appendiceal diameters revealed that there was an obvious cutoff limit between normal pathology and pathology-proven appendicitis. This outcome highlighted the importance of imaging in the diagnosis of acute appendicitis. Radiology's role was central to the management. Conceivably, imaging techniques are strong tools for physicians supporting their diagnosis of AA and they reduce negative appendectomies. Several studies had reported that radiological examination reduced the rate of negative appendectomy from $20 \%$ to $2-14 \%$ [13]. Our results also indicated that the sensitivity of radiological imaging was over $90 \%$. On the other hand, diameter itself does not prove any pathology. The normal diameter of the appendix 
can be as high as $12.8 \mathrm{~mm}$ in adults and majority of normal appendices are larger than $6 \mathrm{~mm}$ [14]. When CT findings are equivocal in patients with suspected appendicitis, appendicitis is encountered in about $30 \%$ but in the case of the appendix measured less than $9 \mathrm{~mm}$ alone, similar to our study findings, the likelihood of appendicitis is much smaller [15]. Yet, strong reinforcements with physical examination and laboratory tests are always should be kept in mind. Ortega-Deballon et al., suggested that patients with a normal WBCC should not undergo appendectomy [16]. Similarly, Atema et al., showed that WBCC and C-reactive protein were important parameters to exclude AA [17].

There are many studies focusing on the optimal criteria for the diagnosis of AA utilizing CT with different types of contrast and routes (e.g. oral, rectal, intravenous) of application. The data from literature highlights the high accuracy of CT in the diagnosis of AA. However, there are convincing results on the high accuracy of CT for the diagnosis of AA. A recent metaanalysis included 9330 patients published in 28 studies reported a significant difference in the negative appendectomy rate (NAR), from $16.7 \%$ when using clinical evaluation without imaging compared to $8.7 \%$ with use of CT [18]. In addition, NAR decreased from the pre-CT era to the post-CT era $(21.5 \%$ to $10 \%$ ) [18]. In 2011, multi-detector row computed tomography (MDCT) showed a sensitivity of $98.5 \%$ and a specificity of $98 \%$ for the diagnosis of AA in 2871 patients [19]. Another metaanalysis included 4341 patients (children and adults) from 31 studies reported a pooled sensitivity and specificity for diagnosis of AA in children of $88 \%$ and $94 \%$, respectively, for US studies and $94 \%$ and $95 \%$, respectively, for CT studies. Pooled sensitivity and specificity for diagnosis of AA in adults were $83 \%$ and $93 \%$, respectively, for US studies, and $94 \%$ and $94 \%$, respectively, for CT studies [20].

The studies and reports detailed above give an overview of the persistent difficulties in the clinical diagnosis of AA in pediatric and adult patients, the usefulness of various clinical scores (which are not commonly used in routine practice) and recent developments of modern imaging techniques focusing on US imaging. To date, US imaging for suspected AA is performed world-wide by radiologists and many physicians of other medical subspecialties, with or without the support of sonographers.

The 2011 American College of Radiology Appropriateness Criteria $^{\star}$ for right lower quadrant pain-suspected appendicitis state that for adult patients with clinical signs of AA the sensitivity and specificity of CT are greater than those of US, but that in pediatric patients, the sensitivity and specificity of graded-compression US can approach those of CT, without the use of ionizing radiation [21].

Patients with a normal WBCC may be acceptable for observation, but several studies had shown that high WBCC could be very important for the diagnosis of AA [22]. Alder et al. [23] demonstrated that the appendix mucosa might develop secondary to viral infections and that uncomplicated cases of viral appendicitis could pass without antibiotics [24].
As a result, an appendix diameter greater than $8 \mathrm{~mm}$ in imaging had a positive predictive value of $90 \%$ for AA patients with normal WBCC. Appendectomy is recommended in patients with normal WBCC with an appendix diameter greater than 8 mm.

\section{Compliance with Ethical Standards}

Ethical Approval: The study was approved by the Akdeniz University School of Medicine Clinical Research Ethics Committee (approval number 917).

Conflict of Interest: The author declares that he has no conflict of interest.

\section{REFERENCES}

[1] Seal A. Appendicitis: a historical review. Can J Surg 1981;24:427-33.

[2] Andersson RE, Hugander A, Thulin AJ. Diagnostic accuracy and perforation rate in appendicitis: association with age and sex of the patient and with appendicectomy rate. Eur J Surg 1992;158:37-41.

[3] Hale DA, Molloy M, Pearl RH, Schutt DC, Jaques DP. Appendectomy: a contemporary appraisal. Ann Surg 1997;225:52-61. doi: 10.1097/00000.658.19970300000003.

[4] Cuschieri J, Florence M, Flum DR, et al. Negative appendectomy and imaging accuracy in the Washington state surgical care and outcomes assessment program. Ann Surg 2008;248:557-63. doi: 10.1097/SLA.0b013e318187aeca.

[5] Wagner PL, Eachempati SR, Soe K, Pieracci FM, Shou J, Barie PS. Defining the current negative appendectomy rate: for whom is preoperative computed tomography making an impact? Surgery 2008;144:276-82. doi: 10.1016/j. surg.2008.03.040.

[6] Poortman P, Oostvogel HJ, de Lange-de Klerk ES, Cuesta MA, Hamming JF. The use of imaging in the case of suspected acute appendicitis: opinion of Dutch surgeons. Ned Tijdschr Geneeskd 2009;153:B376.

[7] Alvarado A. A practical score for the early diagnosis of acute appendicitis. Ann Emerg Med 1986;15:557-64. doi: 10.1016/ S0196-0644(86)80993-3.

[8] Owen TD, Williams H, Stiff G, Jenkinson LR, Rees BI. Evaluation of the Alvarado score in acute appendicitis. J R Soc Med 1992;85:87-8.

[9] Douglas CD, Macpherson NE, Davidson PM, Gani JS. Randomised controlled trial of ultrasonography in diagnosis of acute appendicitis, incorporating the Alvarado score. BMJ 2000;321(7266):919-22. doi: 10.1136/bmj.321.7266.919.

[10] Andersson RE. Meta-analysis of the clinical and laboratory diagnosis of appendicitis. Br J Surg 2004;91:28-37. doi: 10.1002/bjs.4464.

[11] Andersson M, Andersson RE. The appendicitis inflammatory response score: a tool for the diagnosis of acute appendicitis that outperforms the Alvarado score. World J Surg 2008;32:1843-9. doi: 10.1007/s00268.008.9649-y. 
[12] Lahaye MJ, Lambregts DM, Mutsaers E, et al. Mandatory imaging cuts costs and reduces the rate of unnecessary surgeries in the diagnostic work-up of patients suspected of having appendicitis. Eur Radiol 2015;25:1464-70. doi: 10.1007/s00330.014.3531-0.

[13] Raja AS, Wright C, Sodickson AD, et al. Negative appendectomy rate in the era of CT: an 18-year perspective. Radiology 2010;256:460-5. doi: 10.1148/radiol.10091570.

[14] Willekens I, Peeters E, De Maeseneer M, de Mey J. The normal appendix on CT: does size matter? PLoS One 2014;9:e96476. doi: 10.1371/journal.pone.0096476.

[15] Daly CP, Cohan RH, Francis IR, Caoili EM, Ellis JH, Nan B. Incidence of acute appendicitis in patients with equivocal CT findings. Am J Roentgenol 2005;184:1813-20. doi: 10.2214/ ajr.184.6.01841813.

[16] Ortega-Deballon P, Ruiz de Adana-Belbel JC, HernandezMatias A, Garcia-Septiem J, Moreno-Azcoita M. Usefulness of laboratory data in the management of right iliac fossa pain in adults. Dis Colon Rectum 2008;51:1093-9. doi: 10.1007/ s10350.008.9265-9.

[17] Atema JJ, Gans SL, Beenen LF, et al. Accuracy of White Blood Cell Count and C-reactive protein levels related to duration of symptoms in patients suspected of acute appendicitis. Acad Emerg Med 2015;22:1015-24. doi: 10.1111/acem.12746.
[18] Krajevski S, Brown J, Phang PT, Raval M, Brown JC. Impact of computed tomography of the abdomen on clinical outcomes in patients with acute right lower quadrant pain: a metaanalysis. Can J Surg 2011;54:43-53. doi: 10.1503/cjs.023509.

[19] Pickhardt PJ, Lawrence EM, Pooler BD, Bruce RJ. Diagnostic performance of multidetector computed tomography for suspected acute appendicitis. Ann Intern Med 2011;154:78996. doi: 10.7326/0003-4819-154-12-201106.210.00006.

[20] Doria AS, Moineddin R, Kellenberger CJ, et al. US or CT for diagnosis of appendicitis in children and adults? A Meta-Analysis Rad 2006;241:83-94. doi: 10.1148/ radiol.241.105.0913.

[21] Rosen MP, Ding A, Blake MA, et al. ACR Appropriateness Criteria ${ }^{\circledast}$ right lower quadrant pain - suspected appendicitis. J Am Coll Radiol 2011;8:749-55. doi: 10.1016/j.jacr.2011.07.010.

[22] Park HC, Jang MY, Kim IG, et al. Distal appendiceal dilatation in equivocal appendicitis may be a useful sign for prediction of normal appendix. Am Surg. 2010;76:211-4.

[23] Alder AC, Fomby TB, Woodward WA, Haley RW, Sarosi G, Livingston EH. Association of viral infection and appendicitis. Arch Surg 2010;145:63-71. doi: 10.1001/archsurg.2009.250.

[24] Lamps LW. Infectious causes of appendicitis. Infect Dis Clin North Am 2010;24:995-1018. doi: 10.1016/j.idc.2010.07.012. 